\title{
Assessment of Cardiovascular Risk Factors Among University Students: The Gender Factor
}

\author{
Mohammad Y. Gharaibeh ${ }^{\mathrm{a}, \mathrm{e}}$, Karem H Alzoubi ${ }^{\mathrm{b}}$, Omar F. Khabour ${ }^{\mathrm{a}}$, Lubna Tinawia, \\ Rawan Hamad ${ }^{\text {a }}$, Esraa F. Keewan ${ }^{\text {c }}$, Sulaiman K. Matarneh ${ }^{\mathrm{b}}$, Mahmoud A. Alomarid
}

\begin{abstract}
Background: Evidence indicates that the pathophysiological process of cardiovascular (CV) disease begins at early age, though the manifestations of the disease do not appear until middle age adulthood. Risk factors for CV disease, particularly lipoprotein profiles, are affected by physiological abnormalities, and lifestyle related issues. To evaluate prevalence of $\mathrm{CV}$ diseases risk factors among university students and to investigate relation between number of risk factors and body anthropometric, hematological and biochemical indices parameters.
\end{abstract}

Methods: In this cross sectional study, 348 students were randomly recruited. Blood glucose, cholesterol profile (total, HDL, and LDL cholesterol), and triglyceride were measured using standard protocols. Physical activity (PA) level was assessed using the short-form Arabic version of the International Physical Activity Questionnaires (IPAQ).

Results: The most commonly encountered $\mathrm{CV}$ disease risk factor was low levels of HDL-C, followed by physical inactivity, high levels TG, and obese BMI. When stratified by gender, females were less likely to have low HDL-C, and high TG, whereas, males were more likely to have overweight or obese BMI $(\mathrm{P}<0.001)$. About $49 \%$ of the participants had at least one $\mathrm{CV}$ disease risk factor, where as the prevalence of having one, two and three or more CV

\footnotetext{
Manuscript accepted for publication July 20, 2012

${ }^{a}$ Department of Medical Laboratory Sciences, Faculty of Applied Medical Sciences, Jordan University of Science and Technology, Irbid, Jordan

${ }^{\mathrm{b}}$ Department of Clinical Pharmacy, Faculty of Pharmacy, Jordan

University of Science and Technology, Irbid, Jordan

${ }^{c}$ Department of Physiology, Faculty of Medicine, Jordan University of Science and Technology, Irbid, Jordan

${ }^{\mathrm{d}}$ Department of Allied Medical Sciences, Faculty of Applied Medical Sciences, Jordan University of Science and Technology, Irbid, Jordan ${ }^{e}$ Correspondence author: Mohammad Gharaibeh, Dept. of Laboratory Medical Sciences, Faculty of Applied Medical Sciences, Jordan University of Science and Technology, Irbid, 22110, Jordan. Email: Younisgh@just.edu.jo
}

doi: http://dx.doi.org/10.4021/cr198e disease risk factors were $35.7 \%, 9.3 \%$ and $4 \%$, respectively. Additionally, the number of $\mathrm{CV}$ disease risk factors showed strong positive correlation with increases in body fat and bone percentages, glucose, total cholesterol, TG, LDL-C, BMI, and WHR (range of $\mathrm{R}^{2}: 0.17$ to 0.603 ). On the other hand, physical activity, percentages of body water and muscle, HDL-C showed inverse strong correlation with cardiovascular risk factors (range of $\mathrm{R}^{2}$ : -0.239 to -0.412 ).

Conclusions: Results indicate the high prevalence of CV disease risk factors among university students, and stress the need for early intervention programs to counteract these risks.

Keywords: CV disease; Risk factors; University; Students; Jordan

\section{Introduction}

Cardiovascular (CV) diseases are the leading cause of mortality and morbidity in the world even in the developing countries [1]. The manifestations of the diseases increase in middle-aged adults, however, many studies reported signs of atherosclerotic pathogenesis in younger adults and children as young as 5 - 6 years old [2-4].

Serum cholesterol $\leq 200 \mathrm{mg} / \mathrm{dL}$, no history of diabetes, not diagnosed previously with myocardial infarction and no baseline ECG abnormality have been recognized as favorable CV risk profile [5]. Meanwhile, elevated serum cholesterol, diabetes, and obesity have been identified as major risk factors [5]. The relationships of these risk factors with coronary, cerebral, and peripheral vascular diseases have been described as strong, continuous, graded, consistent, independent, predictive, and etiologically significant [6].

Regular physical activity, on the other hand, increases exercise capacity and plays a role in primary and secondary prevention of $\mathrm{CV}$ diseases [7-8]. In addition, physical activity is also considered the most important modifiable risk factor of CV diseases [9]. For example, physical activities promote controlling blood lipid abnormalities, diabetes, and obesity. On the other hand, sedentary lifestyle is associated with high risk of coronary, cerebral, and peripheral vascular diseases and all-cause morbidity and mortality among both 
Table 1. Body, Hematological and Biochemical Variables of the Participants According to Gender

\begin{tabular}{|c|c|c|c|c|}
\hline \multirow{2}{*}{ Variable } & \multirow{2}{*}{$\begin{array}{c}\text { Total } \\
(\text { mean } \pm \text { SD) }\end{array}$} & \multicolumn{3}{|c|}{ Gender } \\
\hline & & $\begin{array}{c}\text { Male } \\
(\text { mean } \pm \text { SD })\end{array}$ & $\begin{array}{c}\text { Female } \\
(\text { mean } \pm \text { SD })\end{array}$ & P-value \\
\hline Body height & $167.69 \pm 9.16$ & $174.97 \pm 7.02$ & $162.75 \pm 6.86$ & 0.000 \\
\hline Body weight & $65.35 \pm 14.83$ & $74.45 \pm 14.48$ & $59.21 \pm 11.56$ & 0.000 \\
\hline Body fat $\%$ & $24.93 \pm 6.20$ & $22.00 \pm 6.47$ & $26.78 \pm 5.26$ & 0.003 \\
\hline Body water\% & $54.78 \pm 4.51$ & $56.93 \pm 4.72$ & $53.43 \pm 3.80$ & 0.003 \\
\hline Body muscle $\%$ & $40.10 \pm 4.81$ & $44.84 \pm 3.59$ & $37.11 \pm 2.53$ & 0.000 \\
\hline BMI & $23.12 \pm 4.10$ & $24.32 \pm 4.31$ & $22.31 \pm 3.76$ & 0.000 \\
\hline WHR & $0.79 \pm 0.07$ & $0.83 \pm 0.06$ & $0.76 \pm 0.06$ & 0.000 \\
\hline Bone mass & $7.57 \pm 2.13$ & $9.91 \pm 1.29$ & $6.12 \pm 0.86$ & 0.948 \\
\hline $\mathrm{RBC}$ & $5.00 \pm 0.55$ & $5.48 \pm 0.38$ & $4.69 \pm 0.39$ & 0.298 \\
\hline HGB & $13.72 \pm 1.56$ & $15.29 \pm 0.91$ & $12.71 \pm 0.93$ & 0.083 \\
\hline $\mathrm{HCT}$ & $43.27 \pm 4.67$ & $47.81 \pm 3.09$ & $40.37 \pm 2.82$ & 0.020 \\
\hline $\mathrm{MCV}$ & $86.81 \pm 6.36$ & $87.34 \pm 5.82$ & $86.46 \pm 6.67$ & 0.341 \\
\hline Glucose & $4.54 \pm 0.49$ & $4.68 \pm 0.58$ & $4.45 \pm 0.40$ & 0.000 \\
\hline Cholesterol & $4.00 \pm 0.74$ & $3.97 \pm 0.79$ & $4.01 \pm 0.71$ & 0.140 \\
\hline $\mathrm{TG}$ & $1.00 \pm 0.52$ & $1.15 \pm 0.59$ & $0.90 \pm 0.44$ & 0.427 \\
\hline HDL & $1.15 \pm 0.33$ & $1.02 \pm 0.29$ & $1.22 \pm 0.33$ & 0.053 \\
\hline LDL & $2.41 \pm 0.62$ & $2.42 \pm 0.65$ & $2.40 \pm 0.60$ & 0.156 \\
\hline
\end{tabular}

Values are in mean \pm SD. RBC: red blood cells; HGB: hemoglobin; HCT: hematocrit; MCV: mean cell volume; TG: triglyceride; HDL: high density lipoprotein; LDL: low density lipoprotein; BMI: body mass index; WHR: waist and hip ratio.

genders at all ages [10]. It is estimated that more than 2 million deaths annually in the world are attributed to physical inactivity [11]. Therefore, implementing physical activity programs in schools, colleges, community centers, and even at job sites is recommended [12].

The prevalence of each risk factor for $\mathrm{CV}$ diseases might differ among different countries and populations, which will affect the implementation of intervention programs. For example, a study that examined physical activity in twenty countries showed wide ranges in the frequency of physical inactivity with $7-43 \%$ and $6-49 \%$ prevalence among men and women respectively [13]. Similarly, a study that examined CV diseases risk factors in several countries from the Middle East and North Africa showed wide variations in the prevalence of obesity, diabetes, hypertension, hyperlipidemia, smoking and physical inactivity among examined populations [14]. For successful prevention programs, several studies have suggested the importance of targeting young 
Table 2. Assessment of CVD Risk Factors Among University Students as Total and Divided by Gender

\begin{tabular}{|c|c|c|c|c|c|}
\hline \multirow{2}{*}{ Variable } & & \multirow{2}{*}{ Total n (\%) } & \multicolumn{2}{|c|}{ Gender } & \multirow{2}{*}{$\begin{array}{l}\text { Pearson Chi- } \\
\text { Square }\end{array}$} \\
\hline & & & Male n (\%) & Female n (\%) & \\
\hline \multicolumn{6}{|l|}{ Glucose } \\
\hline & $\begin{array}{l}\leq 5.89 \mathrm{mmol} / \mathrm{L} \\
>5.89 \mathrm{mmol} / \mathrm{L}\end{array}$ & $\begin{array}{c}313(99.40) \\
2(0.60)\end{array}$ & $\begin{array}{c}120(38.10) \\
2(0.60)\end{array}$ & $\begin{array}{c}193(61.30) \\
0(0.00)\end{array}$ & 0.074 \\
\hline \multicolumn{6}{|c|}{ Cholesterol } \\
\hline & $<5.2 \mathrm{mmol} / \mathrm{L}$ & $299(94.90)$ & $116(36.8)$ & $183(58.10)$ & \multirow{3}{*}{0.513} \\
\hline & $5.2-6.2 \mathrm{mmol} / \mathrm{L}$ & $13(4.1)$ & $4(1.3)$ & $9(2.9)$ & \\
\hline & $>6.2 \mathrm{mmol} / \mathrm{L}$ & $3(1.0)$ & $2(0.60)$ & $1(0.30)$ & \\
\hline \multicolumn{6}{|l|}{ TG } \\
\hline & $\begin{array}{l}\leq 1.7 \mathrm{mmol} / \mathrm{L} \\
>1.7 \mathrm{mmol} / \mathrm{L}\end{array}$ & $288(91.40)$ & $104(33.00)$ & $184(58.40)$ & 0.002 \\
\hline \multicolumn{6}{|l|}{ HDL } \\
\hline & $\begin{array}{l}>1 \mathrm{mmol} / \mathrm{L} \\
\leq 1 \mathrm{mmol} / \mathrm{L}\end{array}$ & $222(70.50)$ & $54(17.10)$ & $\begin{array}{l}154(48.90) \\
39(12.40)\end{array}$ & 0.000 \\
\hline \multicolumn{6}{|l|}{ LDL } \\
\hline & $<3.4 \mathrm{mmol} / \mathrm{L}$ & $251(93.00 \%)$ & $94(34.80 \%)$ & $157(58.10 \%)$ & \multirow{3}{*}{0.895} \\
\hline & $3.4-4.1 \mathrm{mmol} / \mathrm{L}$ & $17(6.3 \%)$ & $7(2.60 \%)$ & $10(3.70 \%)$ & \\
\hline & $>4.1 \mathrm{mmol} / \mathrm{L}$ & $2(0.7 \%)$ & $1(0.4 \%)$ & $1(0.4 \%)$ & \\
\hline \multicolumn{6}{|l|}{ BMI } \\
\hline & $<18.5$ & $30(9.40)$ & $6(1.90)$ & $24(7.50)$ & \multirow{4}{*}{0.001} \\
\hline & $18.5-24.99$ & $207(65.10)$ & $76(23.90)$ & $131(41.20)$ & \\
\hline & $25-29.99$ & $60(18.90)$ & $33(10.40)$ & $27(8.50)$ & \\
\hline & $\geq 30$ & $21(6.60)$ & $13(4.10)$ & $8(2.50)$ & \\
\hline \multicolumn{6}{|l|}{ WHR } \\
\hline & $\begin{array}{l}<0.95(\mathrm{M}), \geq 0.9(\mathrm{~F}) \\
>0.95(\mathrm{M}), \geq 0.9(\mathrm{~F})\end{array}$ & $319(99.10)$ & $128(39.80)$ & $191(59.30)$ & 0.351 \\
\hline Total PA & & & & & 0.255 \\
\hline Low & & $45(13.2)$ & $14(10.7)$ & $31(14.8)$ & \\
\hline Moderate & & $98(28.8)$ & $34(26.0)$ & $64(30.6)$ & \\
\hline High & & 197 (57.9) & $83(63.4)$ & $114(54.5)$ & \\
\hline
\end{tabular}




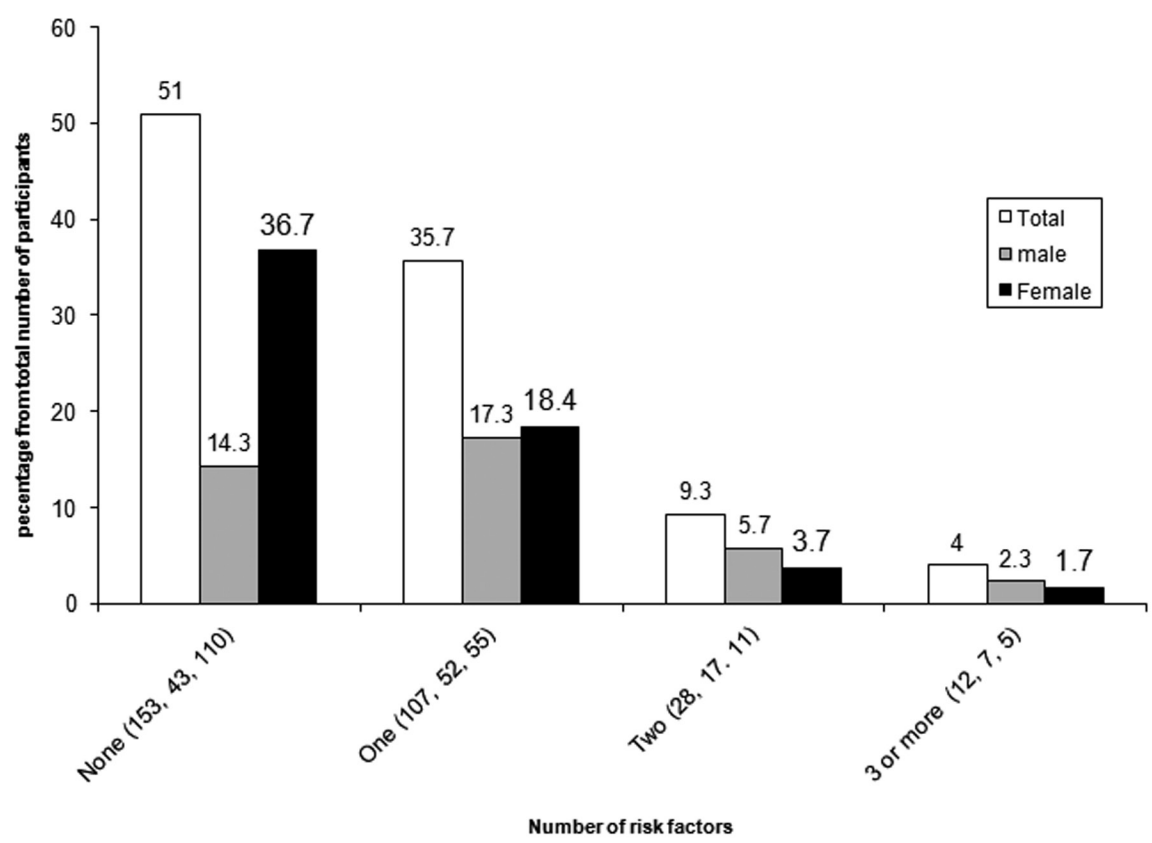

Figure 1. Distribution of $C V$ disease risk factors according to gender $(P=0.001)$. The numbers in brackets represent the number of participants having the specified figure of $\mathrm{CV}$ disease risk factors, while the value above the each column represent the percentage of participants having the particular number of $\mathrm{CV}$ disease risk factors.

adults and identification of risk factors in this population [15-20]. Risk factors of CV diseases in young adults from various countries including Columbia [16], Chile [19], Brazil [18], Japan [17], Serbia [21], and Portugal [15] has been reported, however, not yet from Arab countries. In this study, we evaluated the prevalence of $\mathrm{CV}$ disease risk factors, and the association of these factors with body anthropometric, hematological and biochemical indices among male and female university students in Jordan.

\section{Materials and Methods}

\section{Subjects}

This cross sectional study was conducted at the Jordan University of Science and Technology (JUST) campus during the period from June until September, 2009. Participants were recruited through student's wall advertisements that were posted all over the university campus. Those who responded were invited to a special laboratory to complete a study form that asked about simple demographic information such as age and gender. Thereafter, anthropometric measurements were carried out for the participants. Students were then asked to fast overnight for blood collection. All subjects were healthy individuals 18 to 23 years old. Students with chronic diseases or those taking medications were excluded from the study. After a full explanation of the study details, each participant signed an informed consent approved by the
IRB of JUST in accordance with the principles described in the Declaration of Helsinki, including all amendments and revisions. Data were aggregated and stored in a secure place with access only to the authors and the investigators, to ensure confidentiality.

\section{Cardiovascular risk factors}

Blood glucose, cholesterol profile (total, HDL, and LDL cholesterol), and triglyceride were measured in each participant as described previously [22]. In brief, blood samples were collected in the morning after overnight fasting from the cubital vein in plain and EDTA tubes, and serum/plasma were stored at $-80{ }^{\circ} \mathrm{C}$ until used. $\mathrm{HbA} 1 \mathrm{C}$ was measured from whole blood via immunological assay of hemoglobin A1C using automated clinical chemistry analyzers (Roche, Basel, Switzerland). Glucose, total cholesterol, LDL-C, HDL-C, TG) were measured photometrically using enzymatic assay Kits. CBC and other blood parameters were measured using Automated Hematology Analyzer, Sysmex Xt 2000i (Sysmex Corporation, Kobe, Japan). The result was expressed as $\mathrm{mmol} / \mathrm{L}$.

\section{Anthropometric measures}

Body weight and height were measured to calculate body mass index (BMI) as weight in $\mathrm{kg} /$ height in meters ${ }^{2}$. After measuring the waist and the hip, as the greatest circumference around the pelvic, the ratio (WHR) was calculated. 
Table 3. Pearson's Correlation Between Number of CVD Risk Factors Present and Other Parameters

\begin{tabular}{llll}
\hline & \multicolumn{3}{c}{ Pearson's correlation coefficient } \\
Number of risk \\
factors versus
\end{tabular}

${ }^{* *}$ Correlation is significant at the 0.01 level; ${ }^{*}$ Correlation is significant at the 0.05 level (2-tailed).

Standard classification of BMI and waist circumference cut off values was adopted as previously described [23].

\section{Total Physical activity}

Physical activity (PA) level was assessed using the short-form Arabic version of the International Physical Activity Questionnaires (IPAQ). All individuals in the study were given the questionnaires after detailed description of the questions. The IPAQ is 7 questions designed to evaluate participation in walking, moderate, and vigorous PAs and expressed in MET $\bullet$ min $\bullet \mathrm{wk}^{-1}$. Subsequently, total PA was calculated as walking + moderate + vigorous and categorized into low $(>$ $\left.600 \mathrm{MET} \cdot \min \bullet \mathrm{wk}^{-1}\right)$, moderate $\left(600-1500 \mathrm{MET} \cdot \mathrm{min} \bullet \mathrm{wk}^{-1}\right)$, and high $\left(1500 \mathrm{MET} \cdot \mathrm{min} \bullet \mathrm{wk}^{-1}\right)$ and assigned the values 1,2 , and 3, respectively [24] (http://www.ipaq.ki.se/). The IPAQ was recently validated in several international studies [2527].

\section{Calculation of Risk factors}

The following were considered as risk factors: blood glucose of $>5.89 \mathrm{mmol} / \mathrm{L}$, Total cholesterol of $\geq 5.2 \mathrm{mmol} / \mathrm{L}$, Triglyceride of $>1.7 \mathrm{mmol} / \mathrm{L}, \mathrm{HDl}$ of $\leq 1 \mathrm{mmol} / \mathrm{L}, \mathrm{LDL}$ of 
$\geq 3.4 \mathrm{mmol} / \mathrm{L}$, BMI of $\geq 25$, WHR $>0.95$, and low physical activity $\left(>600 \mathrm{MET} \bullet \mathrm{min} \bullet \mathrm{wk}^{-1}\right)[5,11]$. The number of risk factors represents the sum number of the former condition that is present in each participant.

\section{Statistical analysis}

The obtained data was analyzed using the SPSS (Statistical Package for the Social Sciences, version 17.0, SPSS Inc., Chicago, IL, USA), and presented as means \pm SD for continuous variables and as number and frequencies for categorical variables. The frequency of CV disease risk factors per gender were compared using Pearson's chi square. Associations of lipoprotein profile indices, obesity, glucose and WHR with CV disease risk factors were evaluated by Pearson's correlation. For all statistical analyses, the significance level was set at $\mathrm{P}<0.05$.

\section{Results}

A total of 348 students with a mean age $20.7 \pm 1.7$ years and a male:female ratio of 39:61, agreed to participate in the study. Table 1 shows the health-related fitness, hematological, and biochemical indices of the participants as total and divided by gender. Significant difference was observed between males and females in all body parameters $(\mathrm{P}<0.001)$, glucose and Hematocrit (HCT) levels $(\mathrm{P}<0.05)$.

Table 2 shows the frequency of each CVD risk factors as total and divided by gender. The most common $\mathrm{CV}$ disease risk factors were low HDL-C (29.6\%), and excess weight $(\mathrm{BMI} \geq 25)(25.5 \%)$ with overweight and obesity rates of $18.9 \%$ and $6.6 \%$, respectively, followed by high TG levels $(8.6 \%)$. The prevalence of low HDL-C $(\mathrm{P}=0.000)$, excess obesity $(\mathrm{P}=0.001)$ and high TG $(\mathrm{P}=0.002)$, were greater in the males than the females. The percentage of subjects with no and at least $1 \mathrm{CV}$ disease risk factor were $51 \%$ and $49 \%$, respectively, with $63.8 \%$ and $39.2 \%$ of the males and females, respectively, having at least 1 risk factor. In fact, males were more likely to have $\mathrm{CV}$ disease risk factors as compared to females (Fig. 1; $\mathrm{P}=0.0001$ ). The proportion of subjects having 1,2 , and $\geq 3 \mathrm{CV}$ disease risk factors were $35.7,9.3$ and 4\%, respectively.

As in Table 3, percent body fat, percent bone, glucose, total cholesterol, TG, LDL-C, BMI, and WHR, correlated positively with the number of $\mathrm{CV}$ disease risk factors in the males, females, and the combined genders (range of $\mathrm{R}^{2}$ : 0.17 to 0.603 ). On the other hand, negative correlations were detected between physical activity, body water and percent body muscle, and HDL-C, with the number of $\mathrm{CV}$ disease risk factors in the males, females, and the combined genders (range of $\mathrm{R}^{2}$ : -0.239 to -0.412). Finally, red blood cells (RBCs), hemoglobin (HGB), HCT, and mean cells volume (MCV) were positively correlated with the number of $\mathrm{CV}$ disease risk factors in the study participants as a total, but not per individual gender (Table 3).

\section{Discussion}

Results of this study show high prevalence of several modifiable CV disease risk factors among college students with $49 \%$ had at least 1 risk factor. The presence of risk factors was associated with increases in percent body fat and bone, glucose, total cholesterol, TG, LDL-C, BMI, and WHR. On the other hand, percentages of physical activity, body water and muscle, HDL-C associated inversely with $\mathrm{CV}$ disease risk factors.

In the current study, the most frequent risk factors among the students in chronological order were reduced HDL-C (29.5\%), excess obesity (18.9\%), physical inactivity $(13.2 \%)$, and elevated TG (5.1\%). The occurrence of undesirable blood lipid profile was also reported in Columbian (low HDL-C $=13.3 \%$ ) [16], Chilean (high TC $=29.2 \%$ and LDL-C $=16.2 \%$, and low HDL-C $=5 \%$ ) [28], and Brazilian (high $\mathrm{TC}=17.7 \%$, LDL-C $=10.2 \%$, and $\mathrm{TG}=11.1$, and low HDL-C $=11.1 \%$ ) [18] college students. However, excess obesity (as defined by abdominal circumference or BMI) was prevalent risk factor in the majority of the found studies. It was 45.5 and $24.3 \%$ of the Chilean men and women, respectively [19], 40 and $23 \%$ of the Greek men and women, respectively [29], 18\% in the Brazilians [18], 15.4\% in the Portuguese [15], 11.2\% in the Columbians \%) [16], and $7.27 \%$ in the Srbijein males [20]. The most common risk factors found in Hungarian university students were increased waist circumference, and TG and low HDL-C [30], whereas low HDL-C, and high TG were the most common among Latin American university students [16]. However, in our study, the prevalence of low HDL-C (29.5\%) and high BMI (18.9\%) were much greater, while the prevalence of high TG was comparable to previously reported [16, 20, 30-31]. The prevalence of physical inactivity observed in our study is within the range reported in other university student's populations [16, 20, 30-31].

The greater prevalence of risk factors (i.e low HDL-C, and elevated BM and TG) among the males as compared to females, in our study, was also found in studies from other countries. Differences between genders in the prevalence of risk factors were found also in Portuguese students as the occurrence of hypercholesterolemia was in 15.6 vs. $2.1 \%$ and of hypertension was found in 13.7 vs. $3.5 \%$ of the males and females, respectively [15]. The prevalence of high BMI and abdominal obesity were greater in the university males than the females from Srbija whereas smoking cigarettes was similar in both genders and physical inactivates was greater in the females than the males [20]. The occurrence of abdominal obesity (m: 40 vs. f: $23 \%$ ) and overweight (m: 33.4 vs. f: $27.1 \%$ ) were was also greater in Greek males and were best 
indicators for hypertension and dyslipidaemia, respectively, in both genders [29]. Similar to our study, the male students from Chile were more obese than the females [19]. Abdominal obesity, overweight, and undesirable blood lipid values occurred in greater rates in the males than females in Hungarian students [30]. Additionally, BMI values correlated with waist circumference, total cholesterol, LDL-C, apolipoprotein $\mathrm{B}$, and systolic and diastolic blood pressures in both groups and with HDL-cholesterol in the females [30]. On the other hand, our study showed that the prevalence of physical inactivity was higher in female students than male students. Similar to our finding, high frequency of physical inactivity was reported in female Portuguese [15] and Chilean [19] students than male students. Discrepancies among studies of CVD risk factors are related to several factors including variations in age, geographic distribution, ethnic backgrounds, environment, lifestyles, and genetics of the studied populations. In addition, the variations in the prevalence of risk factors in the different populations and genders highlight the importance of studying these factors in other populations and indicate that each country may need different intervention programs for its population and for each gender.

Percent body fat correlated positively, whereas Percent body muscles correlated negatively with the number of CVD risk factors, indicating the importance of body composition to CV health. This is in accordance with the fact that increased body fat, along with reduced muscles, indicates lower fitness status, which is associated with higher prevalence of CVD. Strong correlation between physical activity and CVD risk factors was reported in this study. This confirms the role of physical activity in prevention of $\mathrm{CV}$ diseases and in controlling blood lipid abnormalities, diabetes, obesity and hypertension [32].

Among the $\mathrm{CV}$ disease risk factors that were not investigated in this study are genetics factors. Several genes were found to modulate susceptibility to CVD including more than 100 loci $[33,34]$. The prevalence of such risk factors among studied population will be a matter of our future research.

\section{Conclusions}

Results of the current study indicate the high prevalence of several modifiable CV disease risk factors among young adult population. As recommended by several health-related organizations such as the World health organization (WHO) and the American College of Sports Medicine, ACSM), prevention and intervention programs of these risk factors should start as early in age as possible.

\section{Acknowledgement}

This work has been done with support from the Deanship of
Research at Jordan University of Science and Technology (139/2009 to M. Y. Gharaibeh).

\section{References}

1. Haddad FH, Omari AA, Shamailah QM, Malkawi OM, Shehab AI, Mudabber HK, Shubaki MK. Lipid profile in patients with coronary artery disease. Saudi Med J. 2002;23(9):1054-1058.

2. Wilund KR, Feeney LA, Tomayko EJ, Weiss EP, Hagberg JM. Effects of endurance exercise training on markers of cholesterol absorption and synthesis. Physiol Res. 2009;58(4):545-552.

3. Kelley GA, Kelley KS. Effects of aerobic exercise on non-high-density lipoprotein cholesterol in children and adolescents: a meta-analysis of randomized controlled trials. Prog Cardiovasc Nurs. 2008;23(3):128-132.

4. Katcher HI, Hill AM, Lanford JL, Yoo JS, Kris-Etherton PM. Lifestyle approaches and dietary strategies to lower LDL-cholesterol and triglycerides and raise HDL-cholesterol. Endocrinol Metab Clin North Am. 2009;38(1):45-78.

5. Pasternak RC, Abrams J, Greenland P, Smaha LA, Wilson PW, Houston-Miller N. 34th Bethesda Conference: Task force \#1--Identification of coronary heart disease risk: is there a detection gap? J Am Coll Cardiol. 2003;41(11):1863-1874.

6. Lowe LP, Greenland P, Ruth KJ, Dyer AR, Stamler R, Stamler J. Impact of major cardiovascular disease risk factors, particularly in combination, on 22year mortality in women and men. Arch Intern Med. 1998;158(18):2007-2014.

7. Morris CK, Froelicher VF. Cardiovascular benefits of physical activity. Herz. 1991;16(4):222-236.

8. Chandrashekhar Y, Anand IS. Exercise as a coronary protective factor. Am Heart J. 1991;122(6):1723-1739.

9. Bauman AE, Smith BJ. Healthy ageing: what role can physical activity play? Med J Aust. 2000;173(2):88-90.

10. Rosamond W, Flegal K, Friday G, Furie K, Go A, Greenlund $\mathrm{K}$, Haase N, et al. Heart disease and stroke statistics--2007 update: a report from the American Heart Association Statistics Committee and Stroke Statistics Subcommittee. Circulation. 2007;115(5):e69-171.

11. Brundtland GH. From the World Health Organization. Reducing risks to health, promoting healthy life. JAMA. 2002;288(16):1974.

12. Fletcher GF, Balady G, Blair SN, Blumenthal J, Caspersen C, Chaitman B, Epstein S, et al. Statement on exercise: benefits and recommendations for physical activity programs for all Americans. A statement for health professionals by the Committee on Exercise and Cardiac Rehabilitation of the Council on Clinical Cardiology, American Heart Association. Circulation. 
1996;94(4):857-862.

13. Bauman A, Bull F, Chey T, Craig CL, Ainsworth BE, Sallis JF, Bowles HR, et al. The International Prevalence Study on Physical Activity: results from 20 countries. Int J Behav Nutr Phys Act. 2009;6(1):21.

14. Mehio Sibai A, Nasreddine L, Mokdad AH, Adra N, Tabet M, Hwalla N. Nutrition transition and cardiovascular disease risk factors in Middle East and North Africa countries: reviewing the evidence. Ann Nutr Metab. 2010;57(3-4):193-203.

15. Brandao MP, Pimentel FL, Silva CC, Cardoso MF. Risk factors for cardiovascular disease in a Portuguese university population. Rev Port Cardiol. 2008;27(1):7-25.

16. Feliciano-Alfonso JE, Mendivil CO, Ariza ID, Perez CE. Cardiovascular risk factors and metabolic syndrome in a population of young students from the National University of Colombia. Rev Assoc Med Bras. 2010;56(3):293298.

17. Furukawa Y, Ehara N, Taniguchi R, Haruna Y, Ozasa N, Saito N, Doi T, et al. Coronary risk factor profile and prognostic factors for young Japanese patients undergoing coronary revascularization. Circ J. 2009;73(8):14591465.

18. Martins Mdo C, Ricarte IF, Rocha CH, Maia RB, Silva VB, Veras AB, Filho MD. Blood pressure, excess weight and level of physical activity in students of a public university. Arq Bras Cardiol. 2010;95(2):192-199.

19. Palomo IF, Torres GI, Alarcon MA, Maragano PJ, Leiva E, Mujica V. [High prevalence of classic cardiovascular risk factors in a population of university students from south central Chile]. Rev Esp Cardiol. 2006;59(11):10991105.

20. Stojanovic D, Visnjic A, Mitrovic V, Stojanovic M. [Risk factors for the occurrence of cardiovascular system diseases in students]. Vojnosanit Pregl. 2009;66(6):453458.

21. Sporisevic L, Krzelj V, Bajraktarevic A, Jahic E. Evaluation of cardiovascular risk in school children. Bosn $\mathrm{J}$ Basic Med Sci. 2009;9(3):182-186.

22. Gharibeh MY, Al Tawallbeh GM, Abboud MM, Radaideh A, Alhader AA, Khabour OF. Correlation of plasma resistin with obesity and insulin resistance in type 2 diabetic patients. Diabetes Metab. 2010;36(6 Pt 1):443449.

23. Peter JV, Billington CJ. Obesity. In Pharmacotherapy: A
Pathophysiologic Approach. Joseph T. DiPiro, Robert L. Talbert. 7th ed. USA. 2008;2437-2453.

24. Alomari MA, Keewan EF, Qhatan R, Amer A, Khabour OF, Maayah MF, Hurtig-Wennlof A. Blood pressure and circulatory relationships with physical activity level in young normotensive individuals: IPAQ validity and reliability considerations. Clin Exp Hypertens. 2011;33(5):345-353.

25. Guthold R, Ono T, Strong KL, Chatterji S, Morabia A. Worldwide variability in physical inactivity a 51-country survey. Am J Prev Med. 2008;34(6):486-494.

26. Craig CL, Marshall AL, Sjostrom M, Bauman AE, Booth ML, Ainsworth BE, Pratt M, et al. International physical activity questionnaire: 12-country reliability and validity. Med Sci Sports Exerc. 2003;35(8):1381-1395.

27. Bauman A, Ainsworth BE, Sallis JF, Hagstromer M, Craig CL, Bull FC, Pratt M, et al. The descriptive epidemiology of sitting. A 20-country comparison using the International Physical Activity Questionnaire (IPAQ). Am J Prev Med. 2011;41(2):228-235.

28. Chiang-Salgado MT, Casanueva-Escobar V, Cid-Cea X, Gonzalez-Rubilar U, Olate-Mellado P, Nickel-Paredes F, Revello-Chiang L. [Cardiovascular risk factors in Chilean university students]. Salud Publica Mex. 1999;41(6):444-451.

29. Bertsias G, Mammas I, Linardakis M, Kafatos A. Overweight and obesity in relation to cardiovascular disease risk factors among medical students in Crete, Greece. BMC Public Health. 2003;3:3.

30. Antal M, Nagy K, Regoly-Merei A, Biro L, Szabo C, Rabin B. Assessment of cardiovascular risk factors among Hungarian university students in Budapest. Ann Nutr Metab. 2006;50(2):103-107.

31. Tak YR, Yun EH, An JY, Lee BS. [Prevalence of cardiovascular risk factors in school-aged children]. J Prev Med Public Health. 2005;38(3):366-372.

32. Morris JN, Clayton DG, Everitt MG, Semmence AM, Burgess EH. Exercise in leisure time: coronary attack and death rates. Br Heart J. 1990;63(6):325-334.

33. Delles C, McBride MW, Padmanabhan S, Dominiczak AF. The genetics of cardiovascular disease. Trends Endocrinol Metab. 2008;19(9):309-316.

34. Jayasinghe SR, Mishra A, Van Daal A, Kwan E. Genetics and cardiovascular disease: Design and development of a DNA biobank. Exp Clin Cardiol. 2009;14(3):33-37. 